\title{
Research on Comprehensive Benefit Evaluation Model of Electrical Energy Alternative With Development Mode of New-type Urbanization
}

\author{
Xiaoyan ZHANG ${ }^{1}$ \& Wen YANG ${ }^{1}$ \& Zhe $\mathrm{LI}^{1}$ \& Cheng LIU ${ }^{1}$,Jianhua ZHOU ${ }^{2}$ \\ ${ }^{1} \mathrm{NARI}$ Technology Development Co., Ltd., Nanjing, China \\ ${ }^{2}$ Jiangsu Electric Power Company Electric Power Research Institute, Nanjing, China
}

KEYWORD: New-type Urbanization; Electrical Energy Alternative; Comprehensive Benefit; Environmental Benefit; Net Income - investment ratio Method

ABSTRACT: In order to analyse feasibility of electrical energy alternative with development mode of new-type urbanization, a method based on net income - investment ratio for comprehensive benefit evaluation model of electrical energy alternative is proposed. The economic benefit, environmental benefit and comprehensive benefit evaluation models are set up. And the net income - investment ratio method is used to realize quantitative analysis of comprehensive benefit of electrical energy alternative. The result shows that the project using electric vehicle instead of conventional vehicle which belongs to "electricity instead of oil" has good economic benefit and environmental benefit, which can also provide theoretical basis for the implementation electrical energy alternative in new-type urbanization.

\section{Introduction}

Urbanization is a process in which the rural population moving to cities and towns in a country or region with the development of the social productive forces, science and technology progress and industrial restructuring, which is an inevitably historical stage in the process of industrialization and modernization. To deal with the problems of energy resources shortage and ecological environment deterioration, all countries are actively exploring a new development mode characterized by new energy and low-carbon economy. China has also put forward a new development concept for urbanization construction, which is intensive, smart, low-carbon and green. In which the concept updates of the traditional town, institutional innovation and technological innovation is emphasized to achieve ecological sustainable development of new industrialization, agricultural modernization and society informatization.

Energy alternative is reflection of requirement for technological progress in energy field and rational utilization of energy. On August 15, 2013, the State Grid Corporation of China published the implementation plan for energy alternative to promote the new mode of energy consumption including "electricity instead of coal, electricity instead of oil and electricity from afar", in order to promote energy saving and break the city haze problems. In some reference, the position and significance of electricity in terminal energy was analyzed. And a more scientific conversion method was proposed to analysis all the terminal energy from two aspects of economy and environment, in which strategies for energy alternative in terminal energy was raised base on the research on feasibility of energy alternative. In some reference, economic benefits and environmental benefits of domestic hot water supply system which is one type of electrical energy alternative were evaluated. In this paper, the comprehensive benefit evaluation model is built to evaluate the comprehensive benefit of "electricity instead of oil". Take electric vehicle for example, the net income - investment ratio method is used to realize quantitative analysis of comprehensive benefit of electrical energy alternative, which can provide theoretical basis for the implementation electrical energy alternative in new-type urbanization.

\section{Methods of Comprehensive Benefit Evaluation of Electrical Energy Alternative}

Economic evaluation is study of the merits of energy-saving programs in the technical feasibility and economic benefits before the project is carried out, comparing the programs and determining the direction of investment to avoid waste of manpower, material and financial resources caused by blind investment. In this paper, the environmental factor is considered on the basis of economic benefit, by quantifying environmental benefit to comprehensive benefit evaluation of electrical energy alterna- 
tive. The environmental benefit is quantified by translating waste gas into environmental damage costs and penalty fees.

The net income - investment ratio method is an economic evaluation method which considers many factors. The net income-investment ratio is the ratio of annual net income in the life of the equipment and annual fees of one-time investment, which is as following:

$\beta=\frac{A_{P}}{A_{I}}$

Where $\beta$ is net income - investment ratio, $A_{P}$ is annual net income of energy-saving project, $A_{I}$ is annual fees of one-time investment of energy-saving project, $A_{P}$ and $A_{I}$ are as following:

$$
\begin{aligned}
& A_{P}=\left\{\sum_{j=1}^{N_{s}} \frac{A_{j}}{(1+i)^{j}}-I_{P}+\frac{F}{(1+i)^{N_{s}}}\right\} \frac{i(1+i)^{N_{s}}}{(1+i)^{N_{s}}-1} \\
& A_{I}=I_{P} \frac{i(1+i)^{N_{s}}}{(1+i)^{N_{s}}-1}
\end{aligned}
$$

Where $N_{s}$ is the life of the equipment(unit: year), $A_{j}$ is net savings of energy-saving project in the first $\mathrm{j}$ year(unit: ten thousand yuan), $I_{P}$ is one-time investment of energy-saving project(unit: ten thousand yuan), $i$ is annual rate of capital, $F$ is salvage value at the end of the life of equipment(unit: ten thousand yuan).

Assuming that net savings each year is equal and written by $A$, so the equation $\beta=\frac{A_{P}}{A_{I}}$ can be simplified as following:

$$
\beta=\frac{A \frac{(1+i)^{N_{s}}-1}{i(1+i)^{N_{s}}}-I_{P}+\frac{F}{(1+i)^{N_{s}}}}{I_{P}}
$$

The comprehensive benefit of various programs can be analyzed and compared according to the results of net income - investment ratio.

\section{Model of Comprehensive Benefit Evaluation of Electrical Energy Alternative}

\section{Model of Economic Benefit Evaluation, environmental benefit}

Only considering economic benefit, the cost of a general project including initial one-time investment, fuel costs, operation and maintenance costs, wages, and annual check-up costs, so the annual cost can be estimated as $A$, which is as following:

$$
A=A_{F}+A_{O M}+A_{S}+A_{A}
$$

Where $A_{F}$ is annual fuel costs(unit: ten thousand yuan), $A_{O M}$ is annual operation and maintenance costs(unit: ten thousand yuan), $A_{S}$ is annual wages(unit: ten thousand yuan), $A_{A}$ is annual checkup costs(unit: ten thousand yuan).

Take one energy project as reference and calculate net income - investment ratio of the other projects, when evaluating the economic benefit using net income - investment ratio method. In addition to the net savings, the financial subsidy should also be included which is ralated to the policies. For example, the government may establish financial subsidy policies in order to promote electrical energy alternative projects and encourage enterprises to participate in them. The subsidy income is zero if there is no subsidy policy.

\section{Model of Environmental Benefit Evaluation}

It is neccesary to quantify the environmental benefit of electrical energy alternative for more accurate study. In this paper, the environmental benefit is monetized to environmental costs. Broadly speaking, environmental costs is the price that the enterprise should pay for the economic loss caused by pollution. Environmental costs generally includes two aspects. One is the environment loss cost, which is the consumption of environmental resources, including the environmental degradation 
caused by pollution and ecological environmental damage caused by excessive consumption of natural resources. The other is the penalty for emission pollutants.

(1) Environment Loss Cost

The environment loss cost electrical energy alternative saves is as following:

$$
C_{e}=\sum_{i=1}^{N} \Delta m_{i} \lambda_{i}
$$

Where $\mathrm{N}$ is type of pollutants, $m_{i}$ is the amount of the first $\mathrm{i}$ type of pollutants, $\lambda_{i}$ is environmental value of the first i type of pollutants.

Table 1 shows the environmental value of main gaseous pollutants.

Table 1. environmental value of main gaseous pollutants.

\begin{tabular}{ccccc}
\hline $\begin{array}{c}\text { gas } \\
\text { name }\end{array}$ & $\mathrm{SO}_{2}$ & $\mathrm{NOx}$ & $\mathrm{CO}$ & $\mathrm{CO}_{2}$ \\
\hline yuan $/ \mathrm{kg}$ & 6.000 & 8.000 & 1.000 & 0.023
\end{tabular}

(2) Penalty for Emission Pollutants.

Penalty for emission pollutants is an effective means to improve environmental protection because of serious environmental pollution caused by the traditional fossil energy consumption, which is also a good way to reflect the environmental benefits of electrical energy alternative. Table 2 shows the punishment orders of magnitude of main gaseous pollutants.

Table 2. punishment orders of magnitude of main gaseous pollutants.

\begin{tabular}{ccccc}
\hline $\begin{array}{c}\text { gas } \\
\text { ame }\end{array}$ & $\mathrm{SO} 2$ & $\mathrm{NOx}$ & $\mathrm{CO}$ & $\mathrm{CO} 2$ \\
\hline yuan $/ \mathrm{kg}$ & 1 & 2 & 0.16 & 0.01 \\
\hline
\end{tabular}

*The pollution charge schedule in Beijing has been adjusted for 10 yuan per kilogram since January 1,2014 . It can be expected that the pollution charge schedule in other provinces will be increased with more and more attention to pollution and emission reduction our country pays.

(3) Environmental Costs

The environmental costs is as following:

$A_{e}=\sum_{i=1}^{N}\left(\Delta m_{i} \lambda_{i}+\Delta V_{i} \mu_{i}\right)$

Where $\mu_{i}$ is punishment orders of magnitude of the first $i$ type of pollutants, $\Delta V_{i}$ is the amount of the first $i$ type of pollutants.

Environmental benefit evaluation is carried out by translating waste gas produced in the process of using energy into environmental costs. The cost the customers should pay for is calculated according to the type and amount of pollutants.

Take one energy project as reference and calculate net income - investment ratio of the other projects, when evaluating the environmental benefit using net income - investment ratio method, which is the same as economic benefit evaluation method.In addition to the net savings, the environmental subsidy should also be included which is ralated to the policies. For example, the government may establish environmental subsidy policies in order to promote electrical energy alternative projects and encourage enterprises to participate in them. The subsidy income is zero if there is no subsidy policy.

In this paper, the electrical energy is considered as pollution-free power when environmental benefit is evaluated and the environmental costs is zero, which is for the end-users.

\section{Comprehensive Benefit Evaluation Method of Electrical Energy Alternative}

Take taxi as the research object in this paper, and the study is carried out on the basis of the following assumptions:

(1) When comparing the comprehensive benefit between traditional taxi and electric taxi, the taxi driver's car behavior (including car mileage, average speed, use frequency, travel/idle time, etc.) is not affected by different vehicle types (that is, the traditional taxi or electric taxi).

(2) The traditional taxi is the fuel automobile.

Take the electric taxi in the trial period in shenzhen for example, and assuming that one traditional taxi costs 100,000 yuan, and one electric taxi (e6 EV from BYD) costs 300,000 yuan. There is 
60,000 yuan from state subsidies and 60,000 yuan from the local government subsidies. So the onetime investment is 180,000 yuan $(300000-60000-60000=180000)$. Assuming that the service time of the taxi is five years, and the taxi travels $400 \mathrm{~km}$ per day, and there is 353 days in service per year (There is one maintenance day per month). The comprehensive power consumption for electric taxi is $25 \mathrm{kWh} / 100 \mathrm{~km}$, and the comprehensive fuel consumption for traditional taxi is $10 \mathrm{~L} / 100 \mathrm{~km}$. According to "the notice about electricity price policy for electric vehicles" issued by National Development and Reform Commission, electric charging facilities in centralized operation enjoy price concessions, which is executed on large industrial electricity price, and with the basic tariff exemption before 2020.The price of electric charging facilities in residential area is executed on residential electricity price. In order to encourage users to reduce charging costs, the price of electric charging facilities is executed on TOU (Time Of Use) price. Assuming that electric taxi charges twice a day, and in average the large industrial electricity accounts for $60 \%$ and the residential electricity accounts for $40 \%$, so the average charging price is 0.58352 yuan $/ \mathrm{kWh}$. The price of gasoline is 6.19 yuan $/ \mathrm{L}$, which is the price on January 4, 2015). The maintenance costs of electric taxi is 6.16 yuan $/ 100 \mathrm{~km}$, and the maintenance costs of traditional taxi is 14 yuan $/ 100 \mathrm{~km}$. Assuming that wages two taxi drivers have the same salary as 5000 yuan/month. The total investment in the service time which is five years, includes investment costs, fuel costs, wages, operation and maintenance costs and other costs (including insurance, accident fees, etc.). The specific parameters are shown in Table 3.

Table 3. data of example.

\begin{tabular}{|c|c|c|}
\hline Project & $\begin{array}{l}\text { tradition- } \\
\text { al taxi }\end{array}$ & $\begin{array}{c}\text { electric } \\
\text { taxi }\end{array}$ \\
\hline one-time investment & 10 & 18 \\
\hline annual fuel costs & 8.7403 & 2.0598 \\
\hline annual wages & 6 & 6 \\
\hline $\begin{array}{l}\text { annual maintenance } \\
\text { costs }\end{array}$ & 1.9768 & 0.8698 \\
\hline other costs & 0.66 & 0.66 \\
\hline $\begin{array}{l}\text { annual environmental } \\
\text { costs }\end{array}$ & 0.1882 & 0 \\
\hline total of 5 years & 67.8265 & 35.948 \\
\hline
\end{tabular}

Taking the traditional fuel taxi for reference to get the net income - investment ratio of electric taxi, and the result is shown in Table 4.

Table 4. net income - investment ratio of electric taxi.

\begin{tabular}{cc}
\hline Conditions & $\beta$ of electric taxi \\
\hline $\begin{array}{c}\text { without environmental bene- } \\
\text { fits }\end{array}$ & 0.69 \\
with environmental benefits & 0.73
\end{tabular}

The result shows that the net income - investment ratio of electric taxi is always greater than0 whether or not to consider the environmental benefits. So the electric taxi project is economically viable. Comparing the results of two kinds of Conditions, it is easy to find that the net income - investment ratio has increased after adding environmental benefits. So the electric taxi is more environmentally effective than traditional fuel taxi. In addition, by analyzing the data of two kinds of taxi scheme, it is shown that the economic benefits of electric taxi mainly comes from fuel costs, so the more miles electric taxi travels, the more costs it saves compared to traditional taxi.

\section{Conclusions}

As to the problem of comprehensive benefit evaluation of electrical energy alternative with development mode of new-type urbanization, The economic benefit, environmental benefit and comprehensive benefit evaluation models are set up. And a method based on net income - investment ratio for comprehensive benefit evaluation model of electrical energy alternative is proposed, which is used to realize quantitative analysis of comprehensive benefit taking the electric taxi for example. The result shows that the project using electric vehicle instead of conventional vehicle has good economic benefit and environmental benefit, which is more obvious with development mode of new-type urbaniza- 
tion, in which there is a variety of forms to use clean energy and a higher proportion of clean electricity.

\section{Acknowledgements}

This work is financially supported by the state grid science and technology program "Research on the mode of new urbanization distribution network and renewable energy utilization".

\section{References}

[1] Dongli Cao et al. 2011. Application and Efficiency Evaluation of Alternative Energy. Power System and Clean Energy 04: 30-34.

[2] Dongxiao Niu et al. 2008. Reseach on electrical energy substitutes in terminal energy. Modern Property Management 23(4): 61-62+65.

[3] Kejun Qian et al. 2008. Environmental Benefits Analysis of Distributed Generation. Proceedings of the CSEE 28(29): 11-15.

[4] Lei Sun et al. 2012. Analysis on Environmental Benefit of Wind Power Generation. Guangdong Electric Power 25(4): 40-43. 